\title{
Effectiveness of training about kinesiotaping in myofascial pain syndrome: A prospective, single-blind, randomized-controlled study
}

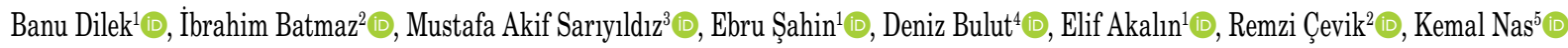 \\ ${ }^{1}$ Department of Physical Medicine and Rehabilitation, Medicine Faculty of Dokuz Eylül University, Izmir, Turkey \\ ${ }^{2}$ Department of Physical Medicine and Rehabilitation, Medicine Faculty of Dicle University, Diyarbakır, Turkey \\ ${ }^{3}$ Department of Physical Medicine and Rehabilitation, Yardımeden Physical Therapy and Rehabilitation Medical Center, Diyarbakır, Turkey \\ ${ }^{4}$ Department of Physical Medicine and Rehabilitation, Kütahya Training and Research Hospital, Kütahya, Turkey \\ ${ }^{5}$ Department of Physical Medicine and Rehabilitation, Medicine Faculty of Sakarya University, Sakarya, Turkey
}

Received: January 31, 2019 Accepted: October 15, 2019 Published online: March 04, 2021

\begin{abstract}
Objectives: In this study, we aimed to investigate whether there was any difference in kinesiotaping (KT) application on the upper trapezius muscle between a trained and untrained physiatrist in the management of patients with myofascial pain syndrome (MPS).

Patients and methods: Between April 2013 and July 2015, a total of 45 patients (44 females, 1 males; mean age $31.9 \pm 8.0$ years; range, 18 to 55 years) with MPS were included in this prospective, single-blind, randomized-controlled study. The patients were randomly divided into two groups. The first group (intervention group, $\mathrm{n}=24$ ) was administered KT band with the muscle in a tense condition according to the muscle technique performed by a trained physiatrist, from the muscle origo toward its insertion point. The second group (control group, $\mathrm{n}=21$ ) received no technique and $\mathrm{KT}$ was applied to the painful area by an untrained physiatrist using a randomly selected method. Primary outcome measures were pain at rest, during activity $(0-10 \mathrm{~cm}$ visual analog scale), and threshold measurement with algometry $\left(\mathrm{kg} / \mathrm{cm}^{2}\right)$. Secondary outcome measures were function (Neck Pain and Disability Scale), degree of palpable muscle spasm, and quality of life (Nottingham Health Profile). All evaluations were performed at baseline, at three and six weeks after the treatment.

Results: There were significant improvements in all parameters in both groups. There were no significant differences in any parameters at six weeks. We demonstrated that KT, which was applied on active trigger points on the upper trapezius muscle by trained and untrained physiatrists, improved pain, palpable muscle spasm, neck function, quality of life, and patient satisfaction degree in patients with MPS.

Conclusion: Our study results show that KT, which is applied by trained and untrained physiatrists, improves pain, palpable muscle spasm, neck function, quality of life in patients with MPS.
\end{abstract}

Keywords: Function, kinesiotaping, myofascial pain syndrome, pain, quality of life, training.

Myofascial pain syndrome (MPS) refers to a type of muscle disease characterized by the presence of tension bands in one or more muscles, and of radiating pain originating from localized areas and trigger points known as hypersensitive areas. ${ }^{[1]}$ Signs and symptoms of MPS originate from trigger points located inside these tense muscle bands. Approximately 30 to $85 \%$ of patients who visit healthcare professionals for musculoskeletal complaint are usually reported to have MPS. ${ }^{[2,3]}$ The most common etiologies of myofascial pain and dysfunction include direct or indirect traumas, vertebral pathologies, exposure to cumulative and repetitive strain, postural dysfunction, and physical incapacity. Medical history and physical examination are diagnostic in MPS. The etiology of MPS is controversial and has not been fully elucidated.

\footnotetext{
Corresponding author: Banu Dilek, MD. Dokuz Eylül Üniversitesi Tıp Fakültesi Fiziksel Tıp ve Rehabilitasyon Anabilim Dalı, 35340 İnciraltı, İzmir, Türkiye. e-mail: banu.dilek@deu.edu.tr 
Genetic, particularly chronic injury caused by acute injury or recurrent microtrauma caused by muscle spikes factors, fatigue and stress are among the most leading causes. ${ }^{[1,2]}$ The primary goal of treatment is to passive the trigger points and to relax tense muscle bands using various treatment modalities. It aims to reduce pain, eliminate impairment of joint motion, and also to eliminate initiating/exacerbating factors of the condition. Treatment modalities include education, medical treatment, tension therapy and spray application, local trigger point injection, post-isometric relaxation, ultrasound, ischemic compression, acupuncture, superficial heat modalities, and laser. ${ }^{[1,4,5]}$

Kinesiotaping (KT), which was developed in 1973 by Dr. Kenzo Kase, a Japanese chiropractor and acupuncture specialist, is a technique implemented using a material called kinesio-tex. ${ }^{[6]}$ It exerts some physiological effects such as reduction of pain and abnormal sensations, supports muscles to facilitate drainage of subcutaneous lymphatic fluid and hemorrhage, and to correct joint derangement. It lifts the skin at the point of application, increases the space between muscles and skin, and reduces the pressure in the affected region. With decreased pressure, stimulation of subcutaneous pain receptors in the region of pain is reduced due to increased blood circulation, thereby, facilitating painless movements. ${ }^{[-9]}$ Currently, KT is used in the management of several conditions such as MPS, subacromial syndrome, hemiplegic shoulder, lymphedema, tendinitis, lateral epicondylitis, patellofemoral pain syndrome, and knee osteoarthritis. ${ }^{[10-13]}$

Although KT is a new taping method, it has been used for the protection of sports trainings and the use of the contents of rehabilitation protocols; however, a literature review has been conducted in this field to implement a new application. Despite its frequent use in practice, there is a limited number of studies on the use of KT in the management of MPS. Although methods of application are as those suggested by Kenzo Kase, different techniques have been introduced to date. Data showing the effect of different techniques on MPS are scarce. In addition, the difference from a placebo without a technical knowledge of application has not been clear, yet. In the present study, therefore, we aimed to investigate whether there was any difference in KT application on the upper trapezius muscle between a trained and untrained physiatrist in the management of patients with MPS.

\section{PATIENTS AND METHODS}

This prospective, single-center, randomizedcontrolled study included a total of 45 patients (44 females, 1 male; mean age $31.9 \pm 8.0$ years; range, 18 to 55 years)) who were admitted to our outpatient clinic with the diagnosis of MPS of the upper trapezius muscle between April 2013 and July 2015. Inclusion criteria were as follows: age between 18 and 60 years; at least one of the first five or the last three of the Travell and Simons' criteria (complaints of regional pain, palpable tension band, severe sensitivity at a point on the tension band, radiating pain and sensory changes from the trigger points to a specific region, reduction in the angle of joint motion, twitching response from palpation or pricking at trigger points following pressure and pain of the trigger points, and sensitive points injection or pain reduction following muscle strain); ${ }^{[14]}$ presence of the necessary sociocultural and socioeconomic status to permit patients in attending outpatient treatment programs; and presence of a trigger point on the upper trapezius muscle. Exclusion criteria were as follows: patients with fibromyalgia syndrome; patients with systemic diseases; presence of significant cervical disc lesion; having trigger point injection within the past one month; having surgery of the neck or shoulder within the past one year; pregnancy; being uncooperative; sensory impairment at the application site and patients with infections; allergy to KT; and having migraine. A written informed consent was obtained from each patient. The study protocol was approved by the Medicine Faculty of Dokuz Eylül University Ethics Committee. The study was conducted in accordance with the principles of the Declaration of Helsinki.

The active trigger points on the upper trapezius muscle causing regional pain were identified after obtaining patient history about age, education status, occupation, and duration of symptoms. The Travell and Simons' criteria were used for the diagnosis of MPS. ${ }^{[14]}$ Block randomization was performed, and the patients were divided into two groups. Trigger points of the upper trapezius muscle were selected for standard procedure in both groups. The first group (intervention group, $\mathrm{n}=24$ ) was administered KT band with the muscle in a tense condition according to the muscle technique performed by a trained physiatrist, from the muscle origo toward its insertion point (Figure 1). In the second group (control group, $n=25$ ), no technique was used and KT was applied to the painful area by an untrained physiatrist using a randomly 


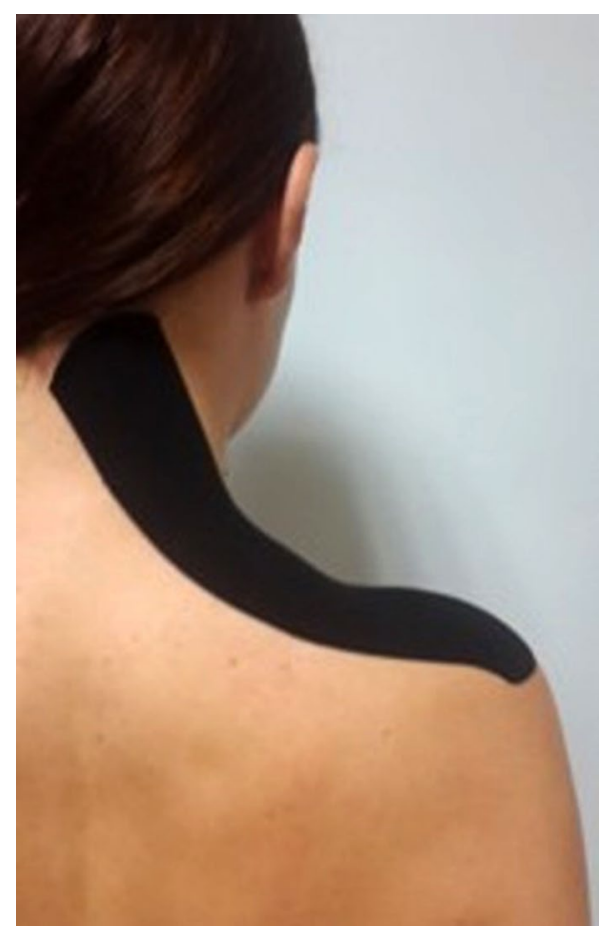

Figure 1. Intervention group-Kinesiotaping.

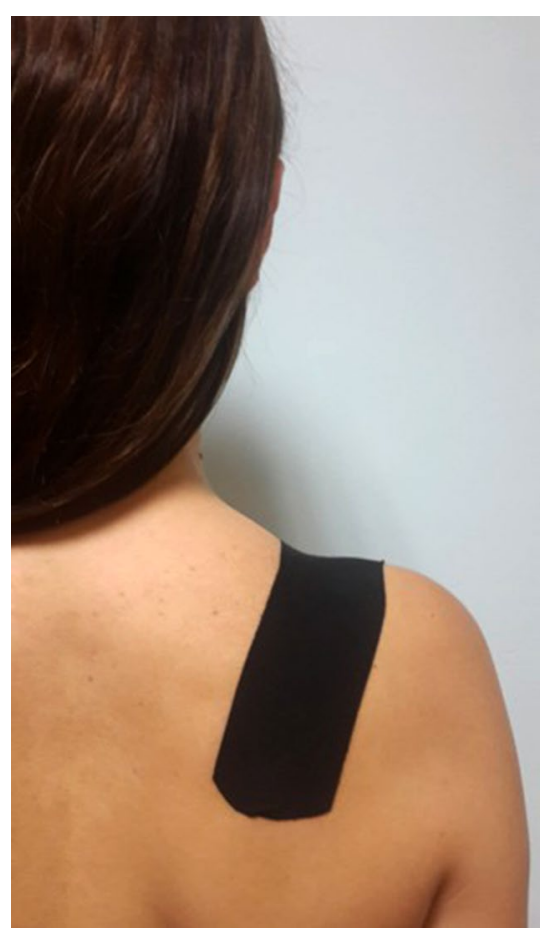

Figure 2. Control group-Kinesiotaping. selected method (Figure 2). Cervical range of motion, stretching, and post-isometric relaxation exercises recommended to both groups during treatment were demonstrated, and the patients were instructed to perform these exercises at home. The bands were applied for a total of six times, after every three days for a total of three weeks. Evaluation was made by a researcher blinded for the study, before, after, and at six weeks after the treatment using the visual analog scale (VAS)-pain, pain threshold measurement by algometry, and Neck Pain and Disability Scale (NPAD)-function. The quality of life was evaluated using the Nottingham Health Profile (NHP). Furthermore, the Likert scale was used to evaluate the patient satisfaction degree at three and six weeks after the treatment. All patients were allowed to take paracetamol as an analgesic, if necessary. They were also instructed to record exercises and medications used.

\section{Outcome measures}

The severity of pain level at rest and during activity and also pain threshold measurement at three and six weeks of treatment were assessed. Pain was evaluated using the $0-10 \mathrm{~cm}$ VAS. The patients were instructed on the numbers from 0 to 10 placed on a $10 \mathrm{~cm}$-line. 0 indicates the absence of pain, 5 indicates moderate pain, and 10 indicates the most severe pain. Accordingly, the patients were required to indicate on a 0 to $10-\mathrm{cm}$ line pain experienced at rest and during activity. An analog algometer (Baseline FDK, Fabrication Enterprises, NY, USA) was used to determine the pain severity. In the sitting position, the metal rod was placed perpendicular to the skin surface at the selected trigger point. The pressure needed to perform was at an increasing rate of $1 \mathrm{~kg} / \mathrm{sec}$. The patient was asked to report the most painful point. The measurement was repeated three times at 1-min intervals for each patient. The average of three measurements was recorded.

Secondary outcomes were the degree of palpable muscle spasm, quality of life, function, and patient satisfaction degree after treatment and also at three and six weeks. The degree of muscle spasm was assessed using a scale of four questions: ${ }^{[15]}$ no spasm $=0$, moderate $\operatorname{spasm}=1$, moderate spasm not limiting the angle of joint motion $=2$, severe spasm limiting the angle of joint motion $=3$, and severe spasm associated with postural deviation $=4$. The quality of life was assessed using the Turkish version of the NHP of which validity and reliability studies were conducted in the Turkish population. ${ }^{[16]}$ This questionnaire evaluates emotional, social, and physical health problems perceived by the patient. It consists of 38 questions with answers in the Yes/No format including six categories of energy, pain, physical mobility, sleep, emotional reaction, and social isolation. We used this questionnaire to evaluate current 


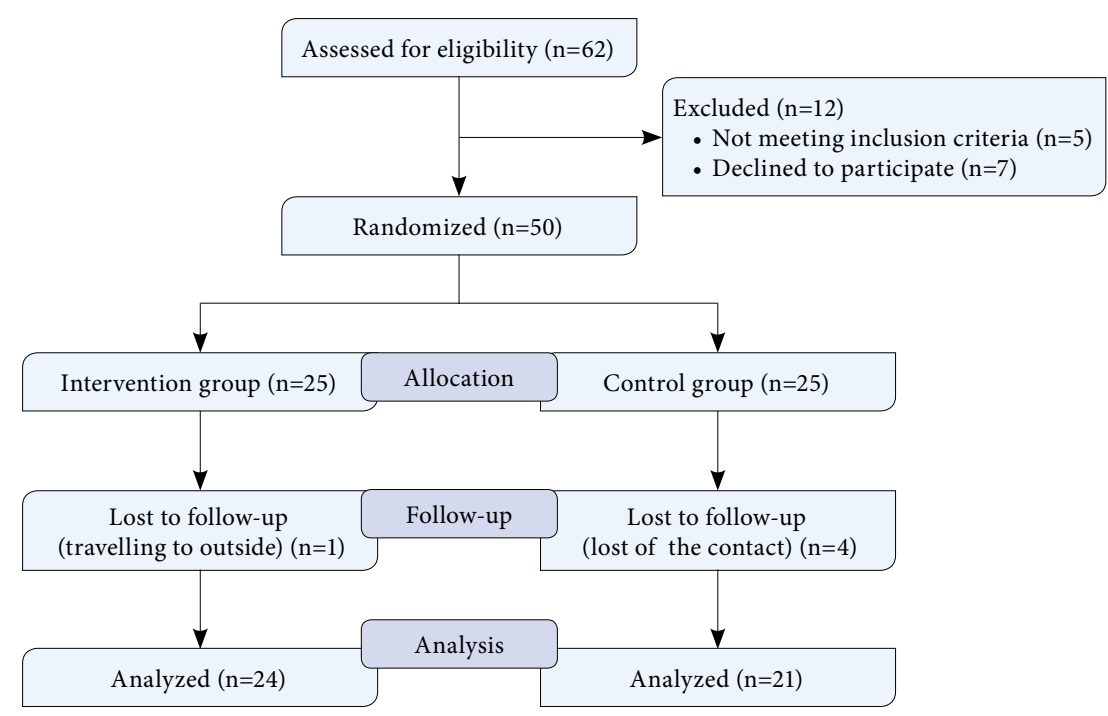

Figure 3. Flow chart of patients.

complaints of the patients. Functional evaluation was performed using the NPAD scale. ${ }^{[17]}$ This measurement was developed for a detailed evaluation of neck pain. The scale was considered more suitable for evaluating the neck pain, as it registered a higher score for neck pain, compared to the waist and leg pain. The NPAD scale consists of 20 questions. The patients indicate a $10 \mathrm{~cm}$-scale for each question. The score for each question ranges between 0 and 5, yielding the total result in sum. Finally, the degree of patient satisfaction was assessed using a questionnaire. It consists of five scores: $0=$ Worse, $1=$ No change, 2 -Mild improvement, $3=$ Good, and $4=$ Excellent. The patients were asked to assess their treatment satisfaction on the Likert scale by selecting the most appropriate choice about their status after treatment, and at three and six weeks after treatment.

\section{Statistical analysis}

Power analysis of the study and sample size calculation were performed using the $\mathrm{G}^{\star}$ Power version 3.08 software (Heinrich-Heine University Düsseldorf, Düsseldorf, Germany). For the primary outcome measures, the power was calculated as $71 \%$ (at rest), 91\% (during activity), and 76\% (pain threshold), respectively. For the secondary outcome measures, the power was calculated as 69\% (degree of palpable muscle spasms), $81 \%$ (function), and $95 \%$ (quality of life).

Statistical analysis was performed using the SPSS for Windows version 15.0 software (SPSS Inc., Chicago, IL, USA). Descriptive data were expressed in mean \pm standard deviation (SD), median (min-max), or number and frequency. The Kolmogorov-Smirnov and Shapiro-Wilk tests were used to analyze normally distributed variables, while non-parametric tests were used for non-normally distributed variables. The continuity correction chi-square test or Fisher's exact test were used for categorical data. The comparison of the data between the groups was carried out using the Mann-Whitney U test. The Wilcoxon test was used to evaluate the pre- and post-KT application differences within the groups. Multiple comparisons were adjusted using the Bonferroni corrections. The Friedman test was used to detect significant differences for repeated measures in each group. A $p$ value of $<0.05$ was considered statistically significant with $95 \%$ confidence interval (CI).

\section{RESULTS}

Of 62 patients who met the inclusion criteria during their routine outpatient visit for MPS, a total of 50 patients with MPS who were willing to participate in the study were included. These patients were randomly and equally allocated into the intervention group and control group; however, a total of five patients were lost to follow-up. Finally, a total of 45 patients completed the study. The study flow chart is shown in Figure 3.

There was no significant difference in age, duration of pain, education status, and occupation between the groups $(\mathrm{p}>0.05)$ (Table 1). However, a significant improvement was observed in both groups after treatment and also at three and six weeks in terms of all pain scores, algometry scores, degree 


\begin{tabular}{|c|c|c|c|c|c|c|c|}
\hline \multicolumn{8}{|c|}{$\begin{array}{c}\text { TABLE } 1 \\
\text { Demographic characteristics of patient groups }\end{array}$} \\
\hline & \multicolumn{3}{|c|}{ Intervention group $(n=24)$} & \multicolumn{3}{|c|}{ Control group $(n=21)$} & \multirow[b]{2}{*}{$p$} \\
\hline & $\mathrm{n}$ & $\%$ & Mean \pm SD & $\mathrm{n}$ & $\%$ & Mean \pm SD & \\
\hline Mean age (year) & & & $32.5 \pm 8.0$ & & & $31.3 \pm 8.1$ & 0.61 \\
\hline Duration of pain (month) & & & $2.9 \pm 1.8$ & & & $3.1 \pm 1.7$ & 0.67 \\
\hline Occupation worker & 1 & 4.2 & & 2 & 9.5 & & 0.476 \\
\hline Civil servant & 6 & 25 & & 6 & 28.6 & & \\
\hline Housewife & 9 & 37.5 & & 3 & 14.3 & & \\
\hline Student & 5 & 20.8 & & 6 & 28.6 & & \\
\hline Other & 3 & 12.5 & & 4 & 19 & & \\
\hline Education elementary school & 2 & 8.3 & & 2 & 9.5 & & 0.800 \\
\hline Middle school & 2 & 8.3 & & 1 & 4.8 & & \\
\hline High school & 7 & 29.2 & & 4 & 19 & & \\
\hline University & 13 & 54.2 & & 14 & 66.7 & & \\
\hline
\end{tabular}

\begin{tabular}{|c|c|c|c|c|c|c|c|c|c|}
\hline \multicolumn{10}{|c|}{$\begin{array}{l}\text { TABLE } 2 \\
\text { Comparison of pain severity between the groups }\end{array}$} \\
\hline & \multicolumn{3}{|c|}{ Intervention group } & \multirow{2}{*}{$\begin{array}{c}\text { Friedman } \\
p\end{array}$} & \multicolumn{3}{|c|}{ Control group } & \multirow{2}{*}{$\begin{array}{c}\text { Friedman } \\
p\end{array}$} & \multirow{2}{*}{$\frac{M W U}{p}$} \\
\hline & Mean \pm SD & Median & Min-Max & & Mean \pm SD & Median & Min-Max & & \\
\hline \multicolumn{10}{|c|}{ Pain at rest (VAS $0-10 \mathrm{~cm}$ ) } \\
\hline Baseline & & 5 & $0-8$ & & & 5 & $0-8$ & & 0.54 \\
\hline Third week & & 1 & $0-6 \dagger$ & $<0.001^{*}$ & & 2.5 & $0-8 \dagger$ & $0.01^{\star}$ & 0.05 \\
\hline Sixth week & & 2 & $0-6 \ddagger$ & & & 1.5 & $0-7 \ddagger$ & & 0.63 \\
\hline Change $\left(0-3^{\text {rd }}\right.$ week $)$ & $1.8 \pm 0.9$ & & & & $1.8 \pm 0.9$ & & & & $0.03^{*}$ \\
\hline \multicolumn{10}{|c|}{ Pain at motion (VAS $0-10 \mathrm{~cm}$ ) } \\
\hline Baseline & & 5 & $1-9$ & & & 6 & $3-10$ & & 0.18 \\
\hline Third week & & 3 & $0-8 \dagger$ & $<0.001^{\star}$ & & 3 & $0-8 \dagger$ & $<0.001^{\star}$ & 0.44 \\
\hline Sixth week & & 3 & $0-7 \ddagger$ & & & 3 & $0-8 \ddagger$ & & 0.90 \\
\hline \multicolumn{10}{|l|}{ Algometry $\left(\mathrm{kg} / \mathrm{cm}^{2}\right)$} \\
\hline Baseline & & 3.7 & $2.2-8$ & & & 3.6 & $2.4-6$ & & 0.44 \\
\hline Third week & & 4.1 & $2.7-9 \dagger$ & $<0.001^{\star}$ & & 4.3 & $2.7-6 \dagger$ & $<0.001^{\star}$ & 0.88 \\
\hline Sixth week & & 4.4 & $2.7-9 \ddagger$ & & & 4.5 & $2.7-11 \ddagger$ & & 0.41 \\
\hline
\end{tabular}

\section{TABLE 3}

Comparison of palpable muscle spasm between the groups

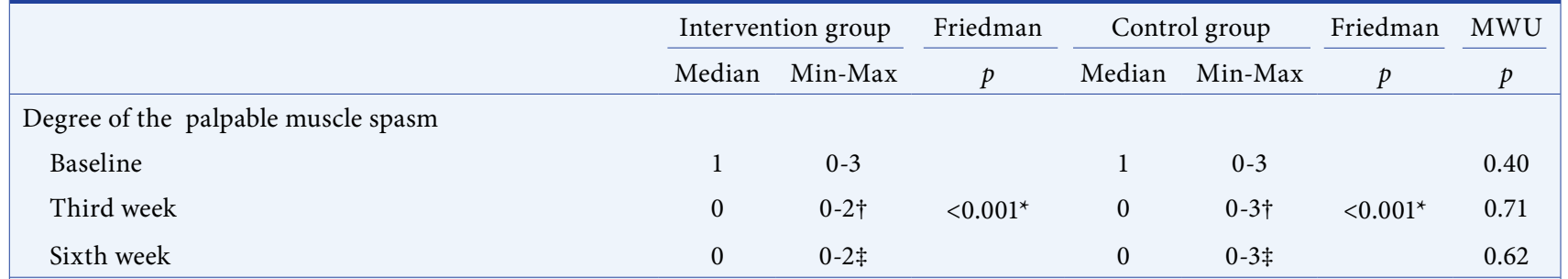

SD: Standard deviation; Min: Minimum; Max: Maximum; MWU: Mann-Whitney U test; ${ }^{*} \mathrm{p}<0.05$; $\uparrow$ Within-group significant difference between baseline and W3; $¥$ Within-group significant difference between baseline and W6. 


\begin{tabular}{|c|c|c|c|c|c|c|c|}
\hline \multicolumn{8}{|c|}{$\begin{array}{c}\text { TABLE } 4 \\
\text { Nottingham health profile scores of patient groups }\end{array}$} \\
\hline & \multicolumn{2}{|c|}{ Intervention group } & \multirow{2}{*}{$\frac{\text { Friedman }}{p}$} & \multicolumn{2}{|c|}{ Control group } & \multirow{2}{*}{$\frac{\text { Friedman }}{p}$} & \multirow{2}{*}{ MWU } \\
\hline & Median & Min-Max & & Median & Min-Max & & \\
\hline \multicolumn{8}{|l|}{ Pain } \\
\hline Baseline & 56.23 & $22.90-94.17$ & \multirow{3}{*}{$<0.001^{\star}$} & 64.77 & $39.22-100$ & \multirow{3}{*}{$<0.001^{\star}$} & 0.12 \\
\hline Third week & 20.48 & $0-70.27 \dagger$ & & 24.12 & $0-67.35 \dagger$ & & 0.08 \\
\hline Sixth week & 12.5 & $0-70.27 \ddagger$ & & 21.49 & $0-67.35 \ddagger$ & & 0.28 \\
\hline \multicolumn{8}{|l|}{ Physical activity } \\
\hline Baseline & 20.79 & $0-66.01$ & \multirow{3}{*}{$0.01^{*}$} & 22.87 & $0-66.01$ & \multirow{3}{*}{0.05} & 0.26 \\
\hline Third week & 11.2 & $0-44.53$ & & 21.13 & $0-55.47 \dagger$ & & 0.13 \\
\hline Sixth week & 10.15 & $0-24.90 \ddagger$ & & 17.15 & $0-55.47 \ddagger$ & & 0.06 \\
\hline \multicolumn{8}{|l|}{ Fatigue } \\
\hline Baseline & 39.20 & $0-100$ & \multirow{3}{*}{$0.005^{\star}$} & 43.20 & $0-100$ & \multirow{3}{*}{0.07} & 0.79 \\
\hline Third week & 35.00 & $0-100 \dagger$ & & 41.20 & $0-100 \dagger$ & & 0.46 \\
\hline Sixth week & 32.20 & $0-100 \ddagger$ & & 39.20 & $0-100 \ddagger$ & & 0.17 \\
\hline \multicolumn{8}{|l|}{ Sleep } \\
\hline Baseline & 24.12 & $0-77.63$ & \multirow{3}{*}{$0.01^{\star}$} & 43.36 & $0-77.63$ & \multirow{3}{*}{$<0.001^{\star}$} & 0.08 \\
\hline Third week & 12.57 & $0-65.06 \dagger$ & & 22.57 & $0-65.06 \dagger$ & & 0.47 \\
\hline Sixth week & 12.67 & $0-77.63 \ddagger$ & & 22.57 & $0-65 \ddagger$ & & 0.73 \\
\hline \multicolumn{8}{|l|}{ Social isolation } \\
\hline Baseline & 0 & $0-22.01$ & \multirow{3}{*}{0.67} & 0 & $0-55.46$ & \multirow{3}{*}{0.13} & 0.57 \\
\hline Third week & 0 & $0-42.14$ & & 0 & $0-55.46$ & & 0.93 \\
\hline Sixth week & 0 & $0-42.14$ & & 0 & $0-55.46$ & & 0.55 \\
\hline \multicolumn{8}{|c|}{ Emotional reaction } \\
\hline Baseline & 16.84 & $0-80.77$ & \multirow{3}{*}{$0.03^{*}$} & 13.78 & $0-80.77$ & \multirow{3}{*}{0.08} & 0.88 \\
\hline Third week & 10.76 & $0-92.78$ & & 10.61 & $0-67.26$ & & 0.57 \\
\hline Sixth week & 10.47 & $0-92.78$ & & 5.23 & $0-67.26$ & & 0.66 \\
\hline
\end{tabular}

\begin{tabular}{|c|c|c|c|c|c|c|c|}
\hline \multicolumn{8}{|c|}{$\begin{array}{c}\text { TABLE } 5 \\
\text { Neck pain and disability scores of patient groups }\end{array}$} \\
\hline & \multicolumn{2}{|c|}{ Intervention group } & \multirow{2}{*}{$\frac{\text { Friedman }}{p}$} & \multicolumn{2}{|c|}{ Control group } & \multirow{2}{*}{$\frac{\text { Friedman }}{p}$} & \multirow{2}{*}{$\frac{\mathrm{MWU}}{p}$} \\
\hline & Median & Min-Max & & Median & Min-Max & & \\
\hline \multicolumn{8}{|c|}{ Neck Pain Disability Index } \\
\hline Baseline & 45 & $22.5-78$ & & 45 & $3-76$ & & 0.99 \\
\hline Third week & 23 & $5-63 \dagger$ & $<0.001^{*}$ & 21 & $0-65 \dagger$ & $<0.001^{*}$ & 1.00 \\
\hline Sixth week & 20 & $0-63 \ddagger$ & & 20 & $10-65 \ddagger$ & & 0.35 \\
\hline
\end{tabular}

TABLE 6

Patient satisfaction degree between the patient groups

\begin{tabular}{|lcccc|} 
& \multicolumn{1}{l}{ Intervention group } & & Control group & \\
\cline { 2 - 2 } & Mean \pm SD & & Mean \pm SD & \\
\hline Patient's satisfaction degree & & & \\
$\quad$ Third week & $3.5 \pm 0.7$ & & $3.1 \pm 0.8$ & 0.10 \\
$\quad$ Sixth week & $3.5 \pm 0.8$ & & $3.4 \pm 0.8$ & 0.96 \\
\hline SD: Standard deviation. & & & \\
\hline
\end{tabular}


of muscle spasm, neck function, and quality of life $(p<0.05)$ (Tables 2-5). On the other hand, there was no significant difference in the evaluation performed before and after treatment, and also at three and six weeks between the two groups ( $p>0.05)$, except for changes of the pain scores at rest at baseline and at three weeks between the groups (Tables 2-5). Also, there was no significant difference in the patient satisfaction degree between the two groups (Table 6).

\section{DISCUSSION}

In this study, we demonstrated that $\mathrm{KT}$, which was applied on active trigger points on the upper trapezius muscle by trained and untrained physiatrists, improved pain, palpable muscle spasm, neck function, quality of life, and patient satisfaction degree in patients with MPS.

Currently, KT is used in the management of sports injuries, postoperative complications, and several painful conditions; however, few studies have focused on MPS with the KT method in the literature. The main goals of the KT procedure are to increase the space beneath the skin and soft tissue, increasing the area of motion, and to facilitate blood and lymphatic circulation, thereby, increasing the rate of improvement. ${ }^{[4]}$ To confirm this hypothesis, Shim et al ${ }^{[18]}$ conducted a study in a rabbit model on wrinkles not only compressing the skin, but also elevating the space. The authors reported a positive effect on opening micro-valves due to the dynamic pressure variation. Through dilatation and contractile properties of the tape during active motion with periodic compression and decompression to the superficial and deep lymphatics, the flow and circulation were improved.

The use of KT in the management of MPS may increase subcutaneous area and, then, increases the drainage of blood flow and lymph fluid, by reducing chemical factors around the trigger point. ${ }^{[4]}$ Wang et al. ${ }^{[19]}$ investigated the effect of KT on MPS. Taping with the insertion to the origin technique was performed on the upper trapezius muscle and a statistically significant pain relief was achieved immediately after the treatment. As a result, the authors suggested that $\mathrm{KT}$ stimulated skin receptors and distension of tau bands. However, no improvement was observed in the control group; although a significant improvement in pain was reported in the intervention group at $24 \mathrm{~h}$. In a case study, García-Muro et al. ${ }^{[5]}$ reported a patient with shoulder pain of myofascial origin who was treated with KT. They observed a significant improvement in the pain (VAS-Pain), algometry, and functional scores with an active range of motion. Furthermore, Wang et al. ${ }^{[19]}$ reported immediate effects on pain reduction after the $\mathrm{KT}$ for upper trapezius muscle.

Previous studies used different taping techniques. Although all procedures of $\mathrm{KT}$ for overlapping disorders were performed according to the Kase's original concept, different practitioners can perform different techniques based on their previous experience and preference, and they may induce the bias. In a randomized placebo-controlled study conducted by Halski et al., ${ }^{[20]}$ cross taping and $\mathrm{KT}$ of the latent trigger points of the upper trapezius muscle were compared. The authors found no significant difference in the bioelectrical activity on the trigger points within a short duration of $24 \mathrm{~h}$, although $\mathrm{KT}$ application was found to reduce the subjective pain sensation. In another study, the effect of KT on pain and muscle strength in patients with MPS was evaluated. ${ }^{[21]}$ A comparison was made in the neutral position using the muscle technique and KT was found to be superior to placebo. However, the aforementioned study did not include a comparison with placebo, but with another technique. Undoubtedly, the limitation for a study on KT is the placebo effect. Some authors have argued that the visual input of different colors and the feeling trapped in the skin may show a positive expectation and cause the patient to feel confident, stable, and secure. ${ }^{[4]}$ However, there is no suitable machine or image data to confirm the effect of taping at any time point or any location. Therefore, our study is important, as it is the first to compare $\mathrm{KT}$ which was applied by both trained and untrained physiatrists between two groups.

Nonetheless, there are some limitations to this study. The lack of a sham or a placebo group is the main limitation. Although no comparison between KT and placebo was made in our study, the efficacy of KT was observed through different applications. The presence of improvement in the control group may be as a result of psychological effects. Moreover, in the control group, application was made on the active trigger point, increasing the lymphatic flow through the elevation of the skin. It may also provide sensory feedback, increasing the patients' awareness. The fact that both groups performed active exercises may have also contributed to the improved outcomes. However, there is still a need for further large-scale studies to confirm these findings and to establish a definitive conclusion. 
In conclusion, our study results show that $\mathrm{KT}$, which is applied on trigger point by trained and untrained physiatrists, may improve pain, palpable muscle spasm, neck function, quality of life, and patient satisfaction degree among patients with MPS. However, training for standard KT application on trigger point seems not to make any additional contribution. Different methods should be investigated on trigger points on MPS in further studies.

\section{Declaration of conflicting interests}

The authors declared no conflicts of interest with respect to the authorship and/or publication of this article.

\section{Funding}

The authors received no financial support for the research and/or authorship of this article.

\section{REFERENCES}

1. Desai MJ, Saini V, Saini S. Myofascial pain syndrome: a treatment review. Pain Ther 2013;2:21-36.

2. Alvarez DJ, Rockwell PG. Trigger points: diagnosis and management. Am Fam Physician 2002;65:653-60.

3. Giamberardino MA, Affaitati G, Fabrizio A, Costantini R. Myofascial pain syndromes and their evaluation. Best Pract Res Clin Rheumatol 2011;25:185-98.

4. Wu WT, Hong CZ, Chou LW. The Kinesio Taping Method for Myofascial Pain Control. Evid Based Complement Alternat Med 2015;2015:950519.

5. García-Muro F, Rodríguez-Fernández AL, Herrerode-Lucas A. Treatment of myofascial pain in the shoulder with Kinesio taping. A case report. Man Ther 2010;15:292-5.

6. Mostafavifar M, Wertz J, Borchers J. A systematic review of the effectiveness of kinesio taping for musculoskeletal injury. Phys Sportsmed 2012;40:33-40.

7. Kase K, Tatsuyuki H, Tomoki O. Development of kinesio tape. In: Kase K, Tatsuyuki H, Tomoki O, editors. Kinesio taping Perfect Manual. USA: Kinesion Taping Association 1996. p. 117-8.

8. Hsu YH, Chen WY, Lin HC, Wang WT, Shih YF. The effects of taping on scapular kinematics and muscle performance in baseball players with shoulder impingement syndrome. J Electromyogr Kinesiol 2009;19:1092-9.
9. Parreira Pdo C, Costa Lda C, Hespanhol LC Jr, Lopes AD, Costa LO. Current evidence does not support the use of Kinesio Taping in clinical practice: a systematic review. J Physiother 2014;60:31-9.

10. Yoshida A, Kahanov L. The effect of kinesio taping on lower trunk range of motions. Res Sports Med 2007;15:103-12.

11. Frazier S, Whitman J, Smith M. Utilization of kinesio tex tape in patients with shoulder pain or dysfunction: a case series. Advanced Healing. 2006;Summer:18-20.

12. Kaya E, Zinnuroglu M, Tugcu I. Kinesio taping compared to physical therapy modalities for the treatment of shoulder impingement syndrome. Clin Rheumatol 2011;30:201-7.

13. Stockheimer KR, Kase $\mathrm{K}$, editors. Kinesio taping for lymphoedema and chronic swelling. Ann Arbor: Kinesio Taping Association; 2004.

14. Travell JG, Simons DG. Myofascial pain and dysfunction. In: Simons DG, Travell JG, Smons LS, Cummings BD, editors. The Trigger Point Manual. Vol 1, upper half of body. Baltimore: Williams and Wilkins; 1992. p. 5-201.

15. Cheshire WP, Abashian SW, Mann JD. Botulinum toxin in the treatment of myofascial pain syndrome. Pain 1994;59:65-9.

16. Kücükdeveci AA, McKenna SP, Kutlay S, Gürsel Y, Whalley $\mathrm{D}$, Arasil T. The development and psychometric assessment of the Turkish version of the Nottingham Health Profile. Int J Rehabil Res 2000;23:31-8.

17. Wheeler AH, Goolkasian P, Baird AC, Darden BU. Item analysis, face and criterion related validity. Spine 1999:1;24-13.

18. Shim JY, Lee HR, Lee DC. The use of elastic adhesive tape to promote lymphatic flow in the rabbit hind leg. Yonsei Med J 2003;44:1045-52.

19. Wang YH, Chen SM, Chen JT, Yen WC, Kuan TS, Hong $\mathrm{CZ}$. The effect of taping therapy on patients with myofascial pain syndrome: a pilot study. Taiwan J Phys Med Rehab 2008;36:145-50.

20. Halski T, Ptaszkowski K, Słupska L, Paprocka-Borowicz M, Dymarek R, Taradaj J, et al. Short-term effects of kinesio taping and cross taping application in the treatment of latent upper trapezius trigger points: a prospective, singleblind, randomized, sham-controlled trial. Evid Based Complement Alternat Med 2015;2015:191925.

21. Öztürk G, Külcü DG, Mesci N, Şilte AD, Aydog E. Efficacy of kinesio tape application on pain and muscle strength in patients with myofascial pain syndrome: a placebocontrolled trial. J Phys Ther Sci 2016;28:1074-9. 